\section{Resilience: for and against}

\author{
John Launer
}

Fashions in medical education rise and fall like fashions in drug treatment. A new idea like "leadership" comes along, educators take it up with enthusiasm, institutions start to offer training in the subject, and research money becomes available to explore its effectiveness. After a while, people start to express scepticism about the idea. Researchers discover how hard it is to prove that training benefits medical students or trainees, let alone having beneficial knock-on effects for patients. Eventually, the unsurprising truth becomes clear. Any form of training, like any drug, will work for some people but not others, in certain situations but not all, and only if a number of clearly defined principles are observed.

Currently, the topic that probably tops the list of educational fashions is "resilience". One recent commentator has described it as part of the "buzzword bingo of health care". ${ }^{1}$ Its rapid rise and subsequent decline provide a perfect model of what happens when enthusiasts in the world of medical education set off at a vigorous sprint, and are then overtaken by sceptics. Only last year, for example, BMJ Careers published an extremely upbeat article with the title "Facing change: develop resilience for staff, associate specialist, and specialty doctors". Its authors reviewed the growing literature on training in resilience. They noted how some teaching hospitals and medical schools around the world are teaching the subject, including in the United States. ${ }^{3}$ They reported on a survey they carried out following a resilience workshop in the north west of England, showing positive responses.

Barely a year later, the same journal has now published another article, with the discouraging title: "Doctors need to be supported, not trained in resilience". ${ }^{4}$ The writers - Eleanor Balme, Clare Gerada and Lisa Page - point out that there are no consistent definitions of resilience, no standardised measurements, no robust studies in what resilience is, what its predictors are, and whether resilience is related to better patient care. They proceed to offer a sophisticated critique

Correspondence to Dr John Launer, Faculty Development, Health Education England, Stewart House, 32 Russell Square, London WC1B 5DN, UK: john.launer@nwl.hee.nhs.uk of the whole enterprise to promote it. Resilience, these writers suggest, is a "complex and dynamic interplay between an individual, the individual's environment, and sociocultural factors". They argue that we should pay attention to all of these dimensions, not just one. They contextualise resilience within a far wider field of concepts include mental health, wellbeing, prevention of burnout, coping strategies, job satisfaction, time management, personality and self-awareness. They make comparisons between training in resilience with other kinds of education including peer group supervision and mentoring.

\section{SYSTEMATIC REVIEWS}

In spite of this, the article as a whole is more nuanced than its title alone suggests. Balme and her colleagues do cite a couple of systematic reviews showing that training in resilience can lead to some modest benefits. The main drift of the article is rightly to caution readers about the need to balance an interest in resilience with an awareness of the organizational and sociocultural factors that "can fracture relationships, create anxiety, and predispose those working in an organisation to create scapegoats, and develop destructive relationships, where the weakest and those from minorities tend to come off worst." Ultimately, in other words, resilience training is no substitute for changing the organizational culture.

On the assumption that resilience may now be reaching the bottom of the enthusiasm curve and is due for an upward bounce, I would like to suggest some reasons why it may still be worth offering training in the subject, while also working in other ways to improve the work climate. The concept of resilience is now widely used in mental health care as a way of emphasising people's resources and capabilities, in contrast to their symptoms and deficits..$^{5}$ As such, it acts as a positive counter to the tendency we all have to pathologize individuals - whether patients or colleagues - who appear to be finding life hard. Although resilience may be a "fuzzy" concept, with indefinite boundaries, it can serve as a node around which many kindred ideas can be aggregated. These include many of those listed by Balme and her team, including wellbeing and self-awareness.

With regard to training in resilience, there is no reason in principle why this cannot include raising awareness about the external factors that impede learners in their development, like unreasonable working conditions, or negative behaviour by teachers and managers. Resilience workshops run by Health Education England, for example, routinely include a discussion of how to escalate concerns

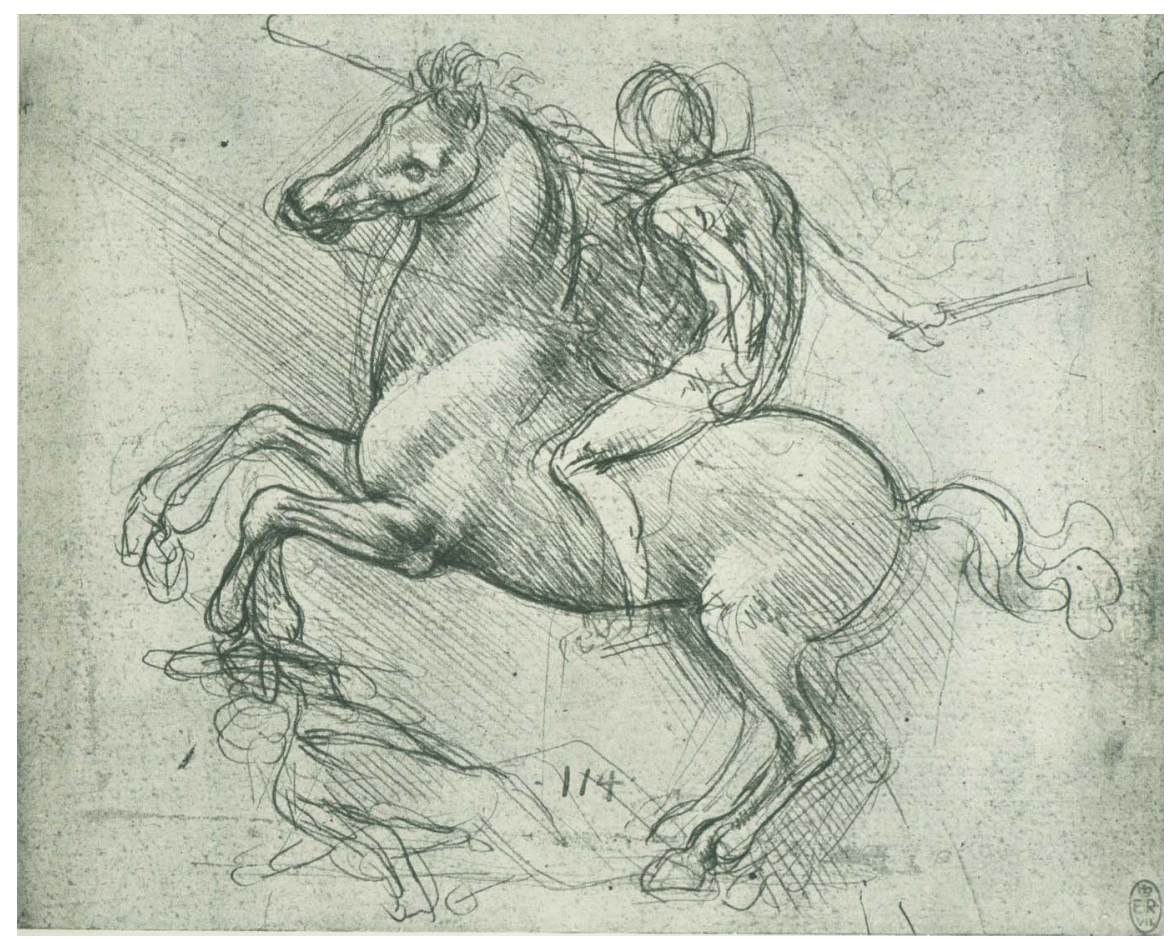

Figure Drawing by Leonardo da Vinci 
about bullying, and how to seek peer support for doing so. ${ }^{6}$ Those taking part in such workshops appear to find it reassuring to discover that some educators regard resilience as the outcome of an interaction between individuals and their organizations, and not just a question of "toughening up". Trainers can also point people towards the different resources available to help with stress management - not just mentoring and peer supervision, but other resources like mindfulness training, counselling, and career support.

Evaluating educational interventions is always a challenge because of the different approaches taken, the different contexts in which these are offered, and other confounding variables. However, as experience accumulates, these obstacles to research can be overcome, particularly by using sound qualitative methods. ${ }^{7}$ In the meantime, I believe that medical educators should themselves show resilience, by adapting in response to legitimate criticism, but maintaining enthusiasm for the subject and continuing to teach it.

Twitter Follow John Launer at @JohnLauner

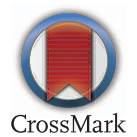

To cite Launer J. Postgrad Med J 2015;91:721-722.

Postgrad Med J 2015;91:721-722.

doi:10.1136/postgradmedj-2015-133827

\section{REFERENCES}

1 Gask L. The problem with resilience. Patching the Soul [blog], 12 Oct 2015. http://lindagask.com/2015/10/ 12/the-problem-with-resilience/ (accessed 2 Nov 2015).

2 Tregoning C, Remington S, Agius S. Facing change: developing resilience for staff, associate specialist, and specialty doctors. BMJ Careers, 22 Jan 2014. http:// careers.bmj.com/careers/advice/view-article.html? id $=20016142$

3 Gabriel BA. Bucking burnout: cultivating resilience in today's physicians. AAMC Reporter, May 2013. https://www.aamc.org/newsroom/reporter/336418/ burnout.html

4 Balme E, Gerada C, Page L. Doctors need to be supported, not trained in resilience. BMJ Careers, 15 Sep 2015. http://careers.bmj.com/careers/advice/ Doctors_need_to_be_supported,_not_trained_in_ resilience

5 Padesky CA, Mooney KA. Strengths-based cognitive behaviour therapy: a four-step model to build resilience. Clin Psychol Psychother 2012;19:283-90.

6 Multiprofessional Faculty Development, Health Education England. Assertiveness and resilience course for multiprofessional healthcare teams. http://store. london.ac.uk/browse/extra_info.asp? compid $=2 \&$ modid $=5 \&$ catid $=123 \&$ prodid $=875$ (accessed 2 Nov 2015).

$7 \mathrm{Ng} \mathrm{S}$, Lingard L, Kennedy TJ. Qualitative research in medical education: Methodologies and methods. In: Swanwick T, ed. Understanding Medical Education: Evidence, Theory and Practice, 2nd edn. London: Wiley-Blackwell. 2013:371-84. 